\title{
Flow Cytometric Characterization of Freshwater Crayfish Hemocytes for the Examination of Physiological Status in Wild and Captive Animals
}

\author{
Sean Taylor and Michael J. Landman* ${ }^{1}$ \\ Sustainable Design, Scion, Te Papa Tipu Innovation Park, \\ 49 Sala Street, Private Bag 3020, Rotorua 3010, New Zealand \\ NichOLAS LiNG \\ Centre for Biodiversity and Ecology Research, University of Waikato, Hamilton, New Zealand
}

\begin{abstract}
Enumeration of invertebrate hemocytes is a potentially powerful tool for the determination of physiological effects of extrinsic stressors, such as hypoxia, disease, and toxicant exposure. A detailed flow cytometric method of broad application was developed for the objective characterization and enumeration of the hemocytes of New Zealand freshwater crayfish Paranephrops planifrons for the purpose of physiological health assessment. Hemocyte populations were isolated by flow cytometric sorting based on differential light scatter properties followed by morphological characterization via light microscopy and software image analysis. Cells were identified as hyaline, semigranular, and granular hemocytes based on established invertebrate hemocyte classification. A characteristic decrease in nuclear size, an increase in granularity between the hyaline and granular cells, and the eccentric location of nuclei in granular cells were also observed. The granulocyte subpopulations were observed to possess varying degrees of granularity. The developed methodology was used to perform total and differential hemocyte counts from three lake populations and between wild and captive crayfish specimens. Differences in total and differential hemocyte counts were not observed among the wild populations. However, specimens held in captivity for $14 \mathrm{~d}$ exhibited a significant $63 \%$ reduction in total hemocyte count, whereas the relative hemocyte proportions remained the same. These results demonstrate the utility of this method for the investigation of subacute stressor effects in selected decapod crustaceans.
\end{abstract}

The hemolymph and hemocyte components of the arthropod circulation are responsible for various protective mechanisms ranging from coagulation and wound repair to cell-mediated immunity (Theopold et al. 2004; Iwanaga and Lee 2005; Jiravanichpaisal et al. 2006). In crustaceans, two major hemocyte groups composed of typically agranular and granular cells are accepted (Hose et al. 1990). These groups may be further differentiated into the hyaline hemocytes and the semigranular and granular hemocytes, which possess some overlapping functional roles (Johansson et al. 2000; Jiravanichpaisal et al. 2006). Hemocyte counts may provide an indication of subacute physiological effect in crustaceans (Smith 1991), and changes in hemocyte count have been shown to be a suitable indicator of stress in some species (Lorenzon et al. 2001).

Greater understanding of species-specific physiology is important because physiological processes are

\footnotetext{
* Corresponding author: michael.landman@norskeskog.com

${ }^{1}$ Present address: Norske Skog Paper Mills (Australia) Limited, Boyer, Tasmania 7140, Australia.
}

Received January 14, 2009; accepted March 11, 2009 Published online October 22, 2009 known to vary considerably between invertebrate taxa. Much of our current understanding of the invertebrate immune system has arisen from the investigation of common research species or those of commercial importance. However, Jiravanichpaisal et al. (2006) suggest that there may be value in examining nonestablished species. Recent interest has developed around the use of the New Zealand freshwater crayfish Paranephrops planifrons as a sentinel species in eutrophic environments because this species has diminished or disappeared in recent decades from parts of its natural range. Among the possible consequences of eutrophication may be increased sediment manganese cycling and bioavailability (Bryant et al. 1997; Tankere et al. 2000; Baden and Neil 2003). This metal has been shown to impair hemocyte function in the Norway lobster Nephrops norvegicus (Hernroth et al. 2004). Thus, declining water quality as a result of eutrophication poses a significant threat to all aquatic organisms but may be of more immediate concern to already threatened species.

The hemocytes of the New Zealand freshwater crayfish have not previously been classified or examined as a tool for ecological assessment. Crustacean hemocyte classification has traditionally been 
based on morphology, cytochemistry, and functional studies (Hose et al. 1990). In many regards, flow cytometry (FC) has superseded microscopic evaluation because FC offers the ability to rapidly and simultaneously discriminate cellular populations based on a variety of variables, such as relative size, complexity, and fluorescent properties (Shapiro 2003). The FC technique has been successfully applied to differential hemocyte investigations and immune responses in several crustacean species (e.g., Owens and O'Neill 1997; Cardenas et al. 2000, 2004; Yip and Wong 2002) and mollusk species (e.g., Xue at al. 2001; Goedken and De Guise 2004; Travers et al. 2008).

The purpose of our study was to identify and characterize the hemocytes of a freshwater crayfish species. Here, we describe a generalized FC protocol that provides rapid hemolymph screening and objective hemocyte characterization, and we detail its application to the New Zealand freshwater crayfish. This method was subsequently used to obtain total and differential hemocyte counts for examining the physiological status of wild and captive animals.

\section{Methods}

Crayfish sampling.-Approximately 50 New Zealand freshwater crayfish (19-51-mm ocular carapace length, 6-86-g total weight) were collected from three sites (10-20 crayfish/site) in the Rotorua Lakes District of the central North Island, New Zealand. Crayfish were hand-collected by scuba divers from Lake Rotorua $\left(38^{\circ} 6.29^{\prime} \mathrm{S}, 176^{\circ} 14.85^{\prime} \mathrm{E}\right)$, Lake Rotoiti $\left(38^{\circ} 3.20^{\prime} \mathrm{S}, 176^{\circ} 25.86^{\prime} \mathrm{E}\right)$, and Lake Rotoma $\left(38^{\circ} 2.57^{\prime} \mathrm{S}, 176^{\circ} 34.96^{\prime} \mathrm{E}\right)$ during May 2008 . Specimens were transported back to the laboratory in 20 -L plastic pails within $1 \mathrm{~h}$ of capture and were anesthetized on ice before size measurement and hemolymph sampling were conducted. An additional 10 Lake Rotoma specimens were retained in the laboratory and housed in 500-L flow-through tanks $(200 \mathrm{~L} / \mathrm{h})$ supplied with constant aeration and dechlorinated Rotorua city tap water at a temperature of $12^{\circ} \mathrm{C}\left(\mathrm{SD}, 0.5^{\circ} \mathrm{C}\right)$. The tanks were maintained on a 16 -h light : 8 -h dark photoperiod. These laboratory-housed crayfish were fed every second day with a selection of chopped vegetables. Rocks were placed in tanks, providing refugia to minimize stress and aggression.

For all hemolymph assessments, $100-\mu \mathrm{L}$ hemolymph samples were withdrawn dorsally from the pericardial sinus between the carapace and first abdominal segment using a $0.5-\mathrm{mL}$ syringe fitted with a 27-gauge needle. A range of anticoagulantsincluding Alsever's solution (Gibco, New Zealand), IsoTon II (Beckman Coulter, USA), and an established crustacean anticoagulant containing citrate and EDTA
(Soderhall and Smith 1983)-were examined and found to be incompatible with crayfish hemolymph for the purposes of this FC evaluation. Instead, syringes were preloaded with $100 \mu \mathrm{L}$ of ice-cold hemolymph fixative solution ( $4 \%$ formaldehyde) so that samples were diluted 1:1 (volume/volume) to maintain cell integrity, thereby preventing clotting and clumping of cells in vitro. Immediately after collection, the hemolymph samples were aspirated into pre-chilled, $0.5-\mathrm{mL}$ centrifuge tubes and gently mixed.

Preliminary flow cytometry evaluation.-Hemolymph samples in fixative solution $(200 \mu \mathrm{L})$ were transferred to pre-chilled, 5-mL polypropylene cytometry tubes (Falcon, USA) previously coated with $4 \%$ bovine serum albumin (BSA; Sigma-Aldrich, Australia) in phosphate-buffered saline (PBS) for $3 \mathrm{~h}$ and were diluted to $1 \mathrm{~mL}$ with ice-cold PBS. Diluted samples were incubated for $15 \mathrm{~min}$ in the dark and on ice with 4 $\mu \mathrm{L}$ of $0.5-\mathrm{mg} / \mathrm{mL} 3,3^{\prime}$-dihexyloxacarbocyanine iodide (DiOC6[3]; Molecular Probes, USA), which is a lipophilic dye that stains the endoplasmic reticulum and is used in measuring FC membrane potential (Shapiro 2003).

A FACSVantage SE flow cytometer (BD Biosciences, USA), which was equipped with DiVa electronics and software, and a $488-\mathrm{nm}$ laser powered at $300 \mathrm{~mW}$ were used to perform sample analysis. Forward scatter (FSC), side scatter (SSC), and fluorescence in the 530/30-nm wavelength range (FL1) were measured. Detector photomultiplier voltages were $125 \mathrm{mV}$ for FSC, $300 \mathrm{mV}$ for SSC, and 250 $\mathrm{mV}$ for $\mathrm{F} 1$, and outputs were viewed in logarithmic mode. Threshold was adjusted between 200 and 5,000 as required to exclude debris and enhance hemocyte resolution at high event counts. The instrument sheath fluid was PBS delivered at $69 \mathrm{kPa}$. Samples were passed through a $70-\mu \mathrm{m}$ nozzle at a flow rate of 1,000 events/s. Between 10,000 and 120,000 events were recorded, depending on resolution between debris and hemocyte populations. Scatter plots (FSC versus SSC) were generated for each treatment. Gating was performed using the DiVa software to define population subsets and to exclude unwanted events. Intact cellular populations corresponded with clusters of events having maximal DiOC6(3) dye uptake (i.e., characterized by narrow, positive fluorescence peaks), which were gated and then highlighted on scatter plots. The SSC events associated with the fluorescence peaks on the fluoroisothiocyanate histogram were gated, and these events were similarly gated on the FSC histogram (Figure 1).

Sorting and characterization of hemocytes.-Cells were sorted based on the previously determined gates. Drop drive frequency and the drop delay were 
optimized as recommended by BD Biosciences (Becton, Dickinson, and Company 2004a). Sorting was performed using a drop drive frequency setting of $22 \mathrm{kHz}$ (amplitude adjusted to 3V) and a drop delay of 13 drops. Sorting purity was adjusted to the Yield Mask setting. Sorted cells were collected in BSAcoated, $5-\mathrm{mL}$ polypropylene tubes containing $3 \mathrm{~mL}$ of PBS supplemented with $0.25 \%$ BSA. The tube holder was cooled with recirculating ice water. Collected cells were spun directly onto polylysine-coated Shandon Cytoslides via a Shandon Cytospin 4 centrifuge (Thermo Electron Corporation, USA). Cytoslides were fitted to BSA-coated cytofunnels with filter cards that were pre-wetted with $50 \mu \mathrm{L}$ of PBS. Samples were centrifuged at 800 revolutions/min for $3 \mathrm{~min}$ and were allowed to air dry for $30 \mathrm{~min}$. Cells were fixed in absolute methanol for $5 \mathrm{~min}$ and subsequently stained with Leishman-Giemsa stain. Slides were air dried again and cover-slipped using Clarion mounting medium (Biomeda, USA). Images of representative cells were captured at $1,000 \times$ magnification via an Olympus BX61 microscope equipped with an SIS ColorView III digital camera. Image analysis to determine cellular and nuclear dimensions was performed using AnalySIS software (LifeScience Series, Olympus, USA). Nucleocytoplasmic ratio was expressed as the percentage of the nuclear area $\left(\mu \mathrm{m}^{2}\right)$ relative to the cellular area.

Hemocyte evaluation in wild and captive crayfish.Total hemocyte counts (THC) and differential hemocyte counts (DHC) were determined for wild and captive specimens (10 crayfish/site or wild versus captive). Accurate cell counts were determined using TruCount tubes (BD Biosciences, USA) containing approximately 50,000 fluorescent-labeled beads. Accurate bead counts per tube were stated on individual batches of tubes. Before FC analysis, we added $1 \mathrm{~mL}$ of PBS to a TruCount tube, vortexed the tube, and added a $100-\mu \mathrm{L}$ aliquot (approximately 5,000 beads) to each sample tube. For each sample, a total of 250 beads were counted. Total or individual population cell counts (cells $/ \mathrm{mL}$ ) were determined using the following formula: ([cells counted $] \times[\sim 5,000$ beads/tube $]) /([250$ beads counted $] \times[0.1-\mathrm{mL}$ hemolymph volume $]$ ).

The DiVa software provides several options to view captured data as single-variable histograms or as dualvariable plots of scatter or fluorescence signal intensity. Two variables may be viewed as dot plots, where each dot represents an event displaying the corresponding value of each variable. Alternatively, in contour plots a third dimension is provided by joining coordinates with similar event counts, as on a topographical map (Becton-Dickinson 2004b). The "20\% probability" software option was used for contour analysis, where
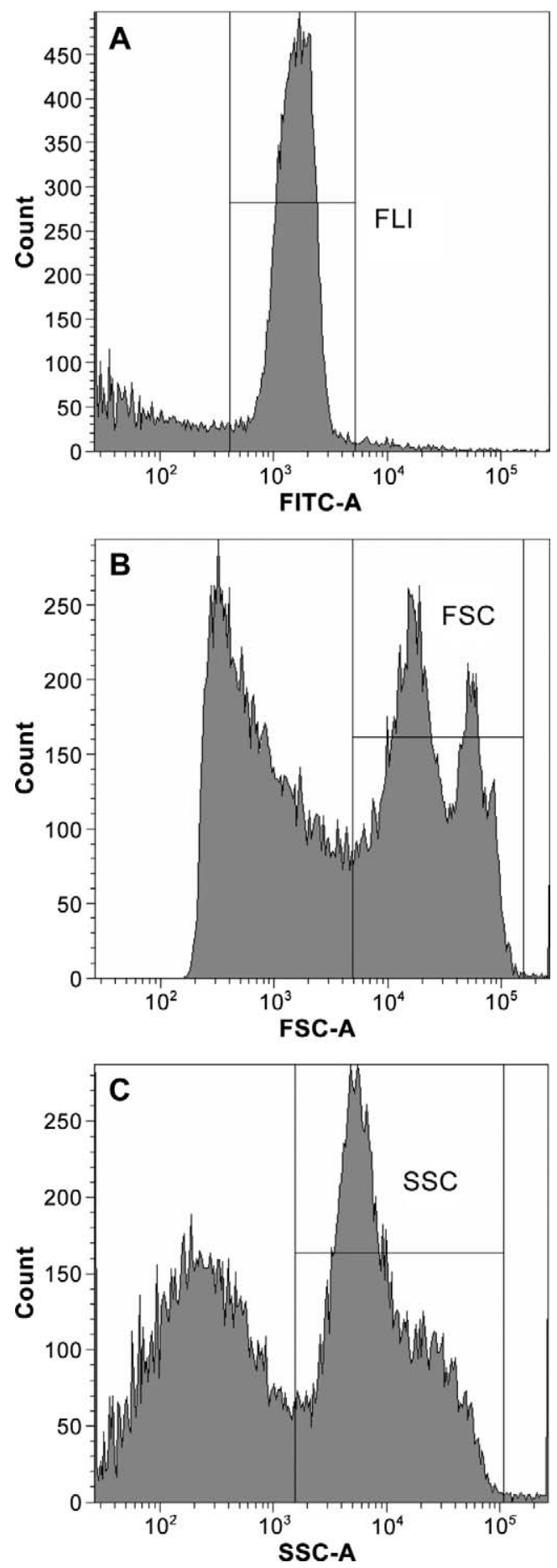

FIGURE 1.-Gating procedure for hemocyte counts on 3,3'dihexyloxacarbocyanine iodide-stained hemolymph samples from New Zealand freshwater crayfish: (A) fluorescent event (FL1) gate (FITC = fluoroisothiocyanate), (B) forward scatter (FSC) subset of FL1 gate, and (C) side scatter (SSC) subset of the FSC gate. 

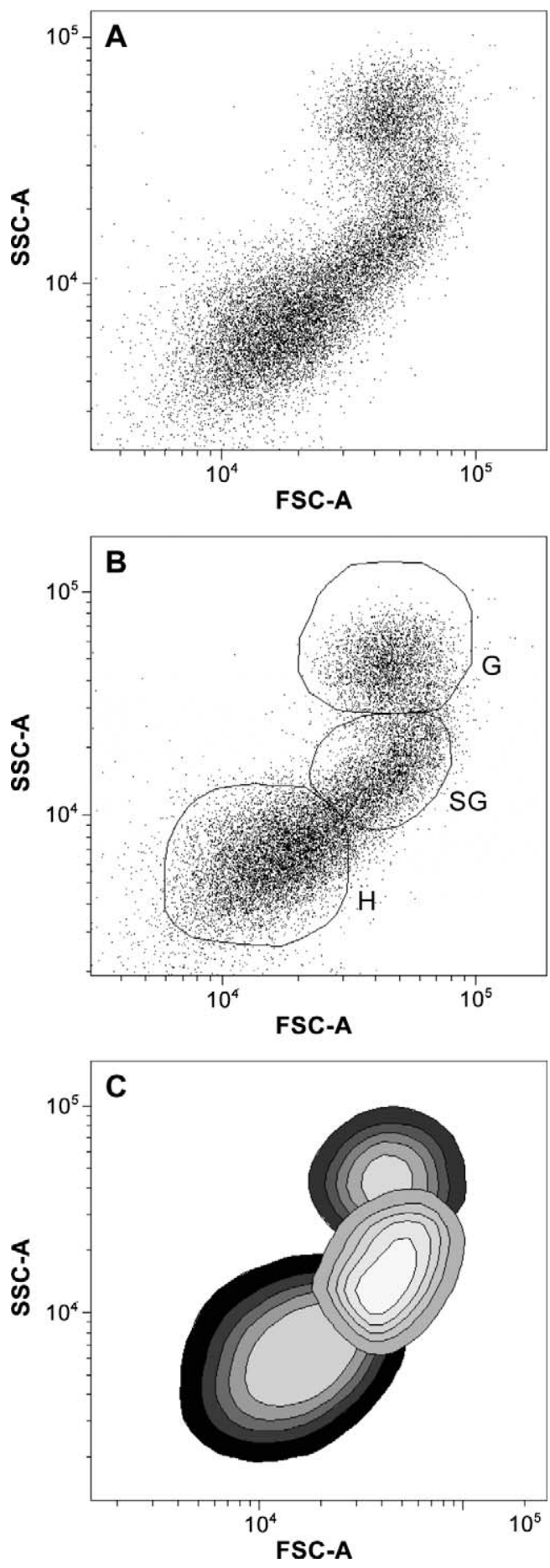

FIGURE 2.-Representative forward scatter (FSC) versus side scatter (SSC) data plots of New Zealand freshwater crayfish hemolymph, showing (A) all cellular events, (B) gating of individual hyaline $(\mathrm{H})$, semigranular (SG), and granular (G) hemocyte populations, and (C) $20 \%$ probability contour plots of hemocyte gates. the area between each contour line contained $20 \%$ of the total event count within each population gate such that the outermost contour represented $10 \%$ of the total number of events, the second contour represented $30 \%$, the third represented $50 \%$, the fourth represented $70 \%$, and the fifth represented $90 \%$. Gates were drawn, by visual inspection, around distinct event clusters on the dot plots. Gates were then spatially adjusted to yield concentric contours, ensuring that resolved populations did not overlap on the contour plots so that a minimum of $95 \%$ of the total event count was accounted for. Thus, a standardized methodology for gating the hemocyte populations was adopted for all samples.

Statistics.-Statistical comparison of THCs and DHCs between sites was performed using one-way analysis of variance (ANOVA; with site as a factor); this was followed by Tukey post hoc analysis when significant site effects were observed. Comparisons of THCs and DHCs between Lake Rotoma specimens sampled immediately upon capture and after $14 \mathrm{~d}$ in captivity were also performed using ANOVA. The THCs were $\log$ transformed before analysis. Because DHCs were measured as proportions, these data were arcsine transformed before analysis (Sokal and Rohlf 1973). All statistical analyses were performed using STATISTICA version 8.0 software. The critical level of statistical significance for all tests was 0.05 .

\section{Results}

Hemocyte populations were successfully resolved on FSC versus SSC data plots via DiOC6(3) staining and scatter parameter gating. Positively fluorescent peaks could be gated on FL1 histograms (Figure 1A), enabling identification and exclusion of broad bands of low-intensity events consistent with debris and autofluorescence (Figure 1B, C). Three event clusters were observed in the typical hemogram of FSC versus SSC (Figure 2A). Gates were drawn around each event cluster (Figure 2B), which were provisionally classified as hyaline, semigranular, and granular hemocyte populations based on scatter properties. Gates were manually adjusted to yield $20 \%$ probability contour plots (Figure 2C), and differential counting and sorting were performed using these gates.

From the defined and sorted FC populations, variations in cellular morphology and response to Leishman-Giemsa staining were evident within each sorted subset, although some population overlap was evident based on scatter and $20 \%$ probability contour plots. Hyaline cells were characterized by a significantly lower cell area than the semigranular and granular cells (Figure 3A; Table 1), and ANOVA indicated that the nuclear areas and nucleocytoplasmic ratios were significantly different for the hemocyte 
types. Hyaline cells had the highest nucleocytoplasmic ratio, and granular cells had the lowest. The cytoplasm and nuclei of all cell types were basophilic to Leishman-Giemsa stain. Nuclear staining of the hyaline cells varied between typically dark blue in the smaller nuclei and light purple in the larger nuclei. The sparse cytoplasm stained light blue, with little evidence of granulation. The semigranular cell nuclei stained between light and dark blue, with the darker color generally associated with smaller nuclei (Figure 3B). Cytoplasmic granularity in these cells varied from being barely discernible to clearly evident as a dense packing of unstained granules within a light-blue cytoplasm. The granular cells were characterized by eccentrically located, small, dark-blue nuclei and faintly to strongly eosinophilic granules that were densely packed within a light-blue cytoplasm (Figure 3C). Each subset also contained a small but unquantified proportion of cells similar in appearance to those characteristic of adjacent gates.

Significant site effects on THC or DHC were not observed among the crayfish populations in the three lakes (Figures 4A, 5A). Total hemocyte counts of Lake Rotoma specimens retained in the laboratory for $14 \mathrm{~d}$ decreased significantly to approximately $37 \%$ of the initial count (Figure 4B). However, the DHC was not affected by reduced THC (Figure 5B).

\section{Discussion}

As far as we are aware, the present work provides the first detailed investigation and characterization of New Zealand freshwater crayfish hemocytes. Formaldehyde was found to be the most effective sampling medium for hemolymph because cell fixation prevented clotting and enabled FC investigation and sorting of intact hemocytes. The FC facilitated a significant level of discrimination between the hemocyte types based on morphology and light scatter, which was further validated by microscopic examination. Three hemocyte populations were identified and found to be morphologically consistent with the generally accepted invertebrate hemocyte classifications. Using the FC protocol developed here, the THCs and DHCs were measured in several wild crayfish populations and also demonstrated a physiological effect of captivity on the circulating hemocytes.

Crustaceans are generally considered to possess three hemocyte types based on morphology: hyaline, semigranular, and granular cells (Bauchau 1981; Johansson et al. 2000). Hose et al. (1990) contend that morphological features alone do not accurately differentiate between the hemocyte categories in decapods and that a combination of morphological, cytochemical, and functional methods are necessary to accurately
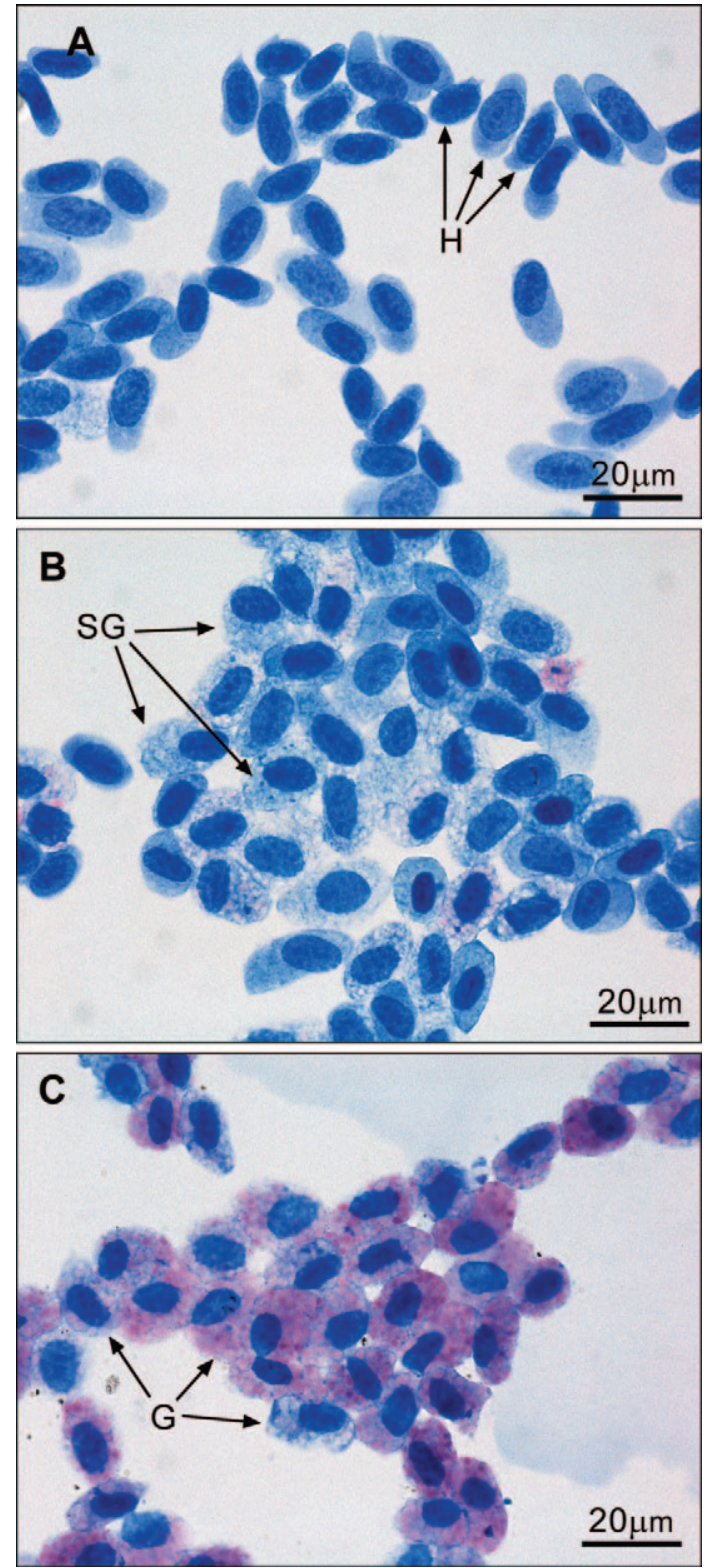

FIGURE 3.- Sorted New Zealand freshwater crayfish hemocytes $(1,000 \times)$ from predefined populations stained with Leishman-Giemsa stain: (A) hyaline $(\mathrm{H})$, showing variation in nuclear size and staining, (B) semigranular (SG), showing variation in nuclear size and staining and cytoplasmic granularity, and (C) granular $(\mathrm{G})$, showing variation in depth of eosinophilic staining of granules.

describe hemocytes. In our study, the FC identified three hemocyte populations based on differential light scatter and fluorescence. Differentiation of sorted populations by Romanowsky (Leishman-Giemsa) staining supported the presence of three hemocyte 
TABLE 1.-Mean (SE in parentheses) length $(L)$ and diameter $(D)$ for sorted hemocytes and nuclei of New Zealand freshwater crayfish $(n=30)$. Different letters indicate significant differences (Tukey post hoc analysis: $P<0.05)$ in cell area and nucleocytoplasmic ratio between cell types.

\begin{tabular}{|c|c|c|c|c|c|c|}
\hline \multirow[b]{2}{*}{ Variable } & \multicolumn{2}{|c|}{ Hyaline } & \multicolumn{2}{|c|}{ Semigranular } & \multicolumn{2}{|c|}{ Granular } \\
\hline & Nucleus & Cell & Nucleus & Cell & Nucleus & Cell \\
\hline Mean $L(\mu \mathrm{m})$ & $11(0.2)$ & $13(0.3)$ & $12(0.2)$ & $15(0.3)$ & $8(0.1)$ & $14(0.4)$ \\
\hline Mean $D(\mu \mathrm{m})$ & $7(0.2)$ & $9(0.3)$ & $7(0.1)$ & $10(0.2)$ & $5(0.2)$ & $10(0.2)$ \\
\hline Mean area $\left(\mu \mathrm{m}^{2}\right)$ & $61(3.0)$ & $104(4.6) \mathrm{z}$ & $48(2.2)$ & $123(4.6) \mathrm{y}$ & $33(1.3)$ & $132(1.0) \mathrm{y}$ \\
\hline Mean nucleocytoplasmic ratio (\%) & $59(2.0) \mathrm{z}$ & & $40(1.7) \mathrm{y}$ & & $25(1.0) \mathrm{x}$ & \\
\hline
\end{tabular}

types and further facilitated the identification of hyaline, semigranular, and granular cells, in agreement with the previous crustacean hemocyte descriptions (Bauchau 1981; Hose et al. 1990; Johansson et al. 2000). The agranular cells possessing a high nucleocytoplasmic ratio were consistent with the identification of crustacean hyaline cells. A characteristic decrease in nuclear size and increase in granularity between the hyaline and granular cells and the eccentric location of nuclei in granular cells were also observed. Using probability contour plots, the FC was
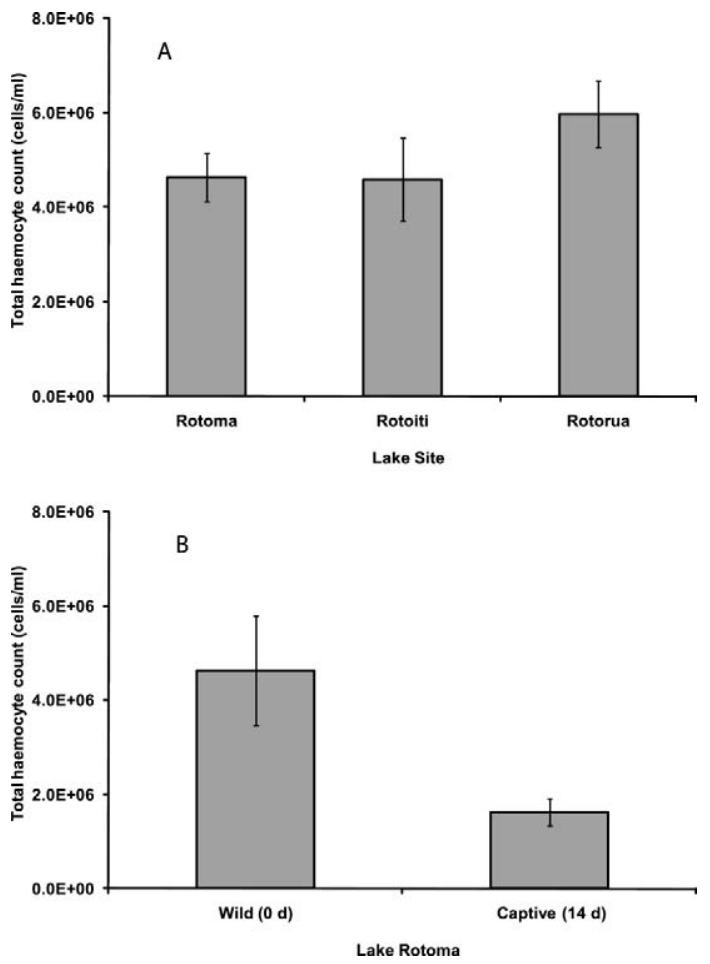

Figure 4.-Comparison of mean $( \pm \mathrm{SE})$ total hemocyte counts (cells/mL) for New Zealand freshwater crayfish: (A) wild specimens at the time of collection from three New Zealand lakes, and (B) Lake Rotoma wild specimens sampled at the time of collection versus those sampled after being held for $14 \mathrm{~d}$ in the laboratory. further capable of differentiating the granular hemocytes into two subpopulations. When examined by light microscopy, the granular subpopulations were observed to possess varying degrees of granularity and differing staining characteristics that were consistent with the identification of semigranular and granular cells. Our results support the suggestion of Sequeira et al. (1995) that FC is more suitable for reliable identification and enumeration of crayfish hemocytes than traditional methods, such as subjective morphological investigations using smears.
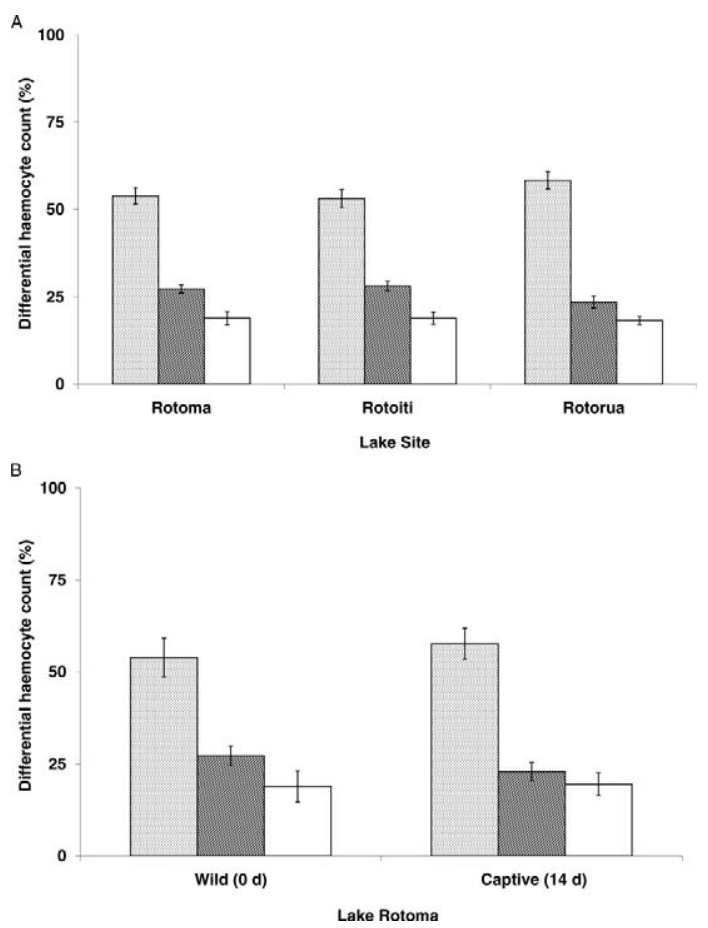

FiguRE 5.-Mean ( \pm SE) differential hemocyte counts for New Zealand freshwater crayfish: (A) wild specimens sampled at the time of collection from three New Zealand lakes, and (B) Lake Rotoma wild specimens sampled at collection versus those sampled after being held for $14 \mathrm{~d}$ in the laboratory. Columns represent hyaline (dotted), semigranular (lined), and granular (unshaded) cells. 
Although differences in THCs or DHCs of wild New Zealand freshwater crayfish were not observed, the dramatic reduction of THC in captive crayfish was indicative of a definite response to capture and captivity in this species. Regardless of the possible reasons for these changes, reduced circulating hemocyte numbers represents an increased risk of infection (Le Moullac and Haffner 2000). Moreover, the 63\% reduction in THC exhibited by the captive crayfish in our study is similar to the observed threshold of mortality (approximately $30 \%$ of original THC) in two other decapod crustacean species, the sand shrimp Crangon crangon and the rockpool prawn Palaemon elegans (Lorenzon et al. 1999). Severe or prolonged reduction of THC may have significant implications for long-term survival in captivity and may partially explain the frequently encountered difficulties in keeping New Zealand freshwater crayfish in the laboratory.

Changes in the circulating hemocyte numbers of crustaceans have been observed in response to a variety of stressors ranging from bacterial and fungal infection (Cheng and Chen 2001; Jiravanichpaisal et al. 2001), the bacterial endotoxin lipopolysaccharide (LPS; Lorenzon et al. 1999, 2002; Cardenas et al. 2004), toxicant exposure (Smith et al. 1995; Lorenzon et al. 2001; Ward et al. 2006), and capture stressors, such as air exposure, handling, and transportation (Jussila et al. 1997; Fotedar et al. 2001; Tsvetnenko et al. 2001; Lorenzon et al. 2008). However, changes in circulating hemocyte numbers may be rapid and show nearbaseline recovery within hours to days. For example, Lorenzon et al. (2001) demonstrated that short-term (96-h) exposures to heavy metal solutions were capable of reducing THC in the rockpool prawn over the first 8 $\mathrm{h}$ of exposure; THC generally returned to normal by 16 $\mathrm{h}$ postexposure. Lorenzon et al. (2002) also demonstrated a similar THC decline and recovery in response to LPS injection in this species. The prolonged depression of circulating hemocytes of New Zealand freshwater crayfish in our study may be related to poor recovery after capture or continued stress associated with confinement.

Alternatively, various environmental factors, such as fluctuations in temperature and dissolved oxygen, may also influence the crustacean immune system on a daily basis (Le Moullac et al. 1998; Le Moullac and Haffner 2000), whereas captive crustaceans are typically subjected to constant ambient conditions. Wild crustaceans are also likely to experience a greater natural abundance of bacteria, where increased hemocyte numbers would presumably favor survival in the wild. Although many studies have documented decreased circulating hemocytes in response to challenge, other studies have reported hemocyte proliferation. Sequeira et al. (1996) observed threeto sixfold increases in circulating hemocytes in response to LPS stimulation and fungal infection in the kuruma prawn Penaeus japonicus. Latex beads have also been shown to cause hemocyte proliferation in the freshwater Danube crayfish Astacus leptodactylus (Giulianini et al. 2007). Jussila et al. (2001) demonstrated an approximately twofold increase in THC of the western rock lobster Panulirus cygnus at 1 $\mathrm{h}$ postexercise. Thus, an alternative explanation to stress-induced reductions in THC is that captive New Zealand freshwater crayfish reverted to or experienced a change in baseline physiological status owing to recovery from capture, improved water quality, exposure to constant ambient conditions, or a combination of these factors.

This study demonstrated that FC was suitable for the differentiation and enumeration of circulating hemocytes of the New Zealand freshwater crayfish and is a valuable tool for the assessment of physiological status. It is anticipated that future hematological investigations using this species will provide early indication of ecosystem stress and thus broaden the scope of environmental impact assessments using this environmentally relevant species.

\section{Acknowledgments}

This research was funded by Environment Bay of Plenty and through a New Zealand Foundation for Research Science and Technology contract (C04X0301) with Scion. We are grateful for the field assistance of Jeroen Brijs during specimen collection and for Iwi consultation with Roku Mihinui and Hera Smith of the Te Arawa Lakes Trust, facilitated by Tupara Morrison (Scion). All animal research was performed in accordance with the Scion Code of Ethical Conduct for the handling of animals and the New Zealand Animal Welfare Act of 1999.

\section{References}

Baden, S. P., and D. M. Neil. 2003. Manganese accumulation by the antennule of the Norway lobster Nephrops norvegicus (L.) as a biomarker of hypoxic events. Marine Environmental Research 55:59-71.

Bauchau, A. G. 1981. Crustaceans. Pages 385-420 in N. A. Ratcliffe and A. F. Rowley, editors. Invertebrate blood cells. Academic Press, London.

Becton, Dickinson, and Company. 2004a. Sorting. Pages 73114 in BD digital electronics option user's guide. Becton, Dickinson, and Company, San Jose, California.

Becton, Dickinson, and Company. 2004b. Tools for data analysis. Pages 150 in BD FACSDiVa software reference manual. Becton, Dickinson, and Company, San Jose, California. 
Bryant, C. L., J. G. Farmer, A. B. MacKenzie, A. R. BaileyWatts, and A. Kirika. 1997. Manganese behavior in the sediments of diverse Scottish freshwater lochs. Limnology and Oceanography 42:918-929.

Cardenas, W., J. R. Dankert, and J. A. Jenkins. 2004. Flow cytometric analysis of crayfish haemocytes activated by lipopolysaccharides. Fish and Shellfish Immunology 17:223-233.

Cardenas, W., J. A. Jenkins, and J. R. Dankert. 2000. A flow cytometric approach to the study of crustacean cellular immunity. Journal of Invertebrate Pathology 76:112119.

Cheng, W., and J.-C. Chen. 2001. Effects of intrinsic and extrinsic factors on the haemocyte profile of the prawn, Macrobrachium rosenbergii. Fish and Shellfish Immunology 11:53-63.

Fotedar, S., E. Tsvetnenko, and L. H. Evans. 2001. Effect of air exposure on the immune system of the rock lobster Panulirus cygnus. Marine and Freshwater Research 52:1351-1355.

Giulianini, P. G., M. Bierti, S. Lorenzon, S. Battistella, and E. A. Ferrero. 2007. Ultastructural and functional characterization of circulating hemocytes from the freshwater crayfish Astacus leptodactylus: cell types and their role after in vivo artificial non-self challenge. Micron 38:49-57.

Goedken, M., and S. De Guise. 2004. Flow cytometry as a tool to quantify oyster defence mechanisms. Fish and Shellfish Immunology 16:539-552.

Hernroth, B., S. P. Baden, K. Holm, T. Andre, and I. Soderhall. 2004. Manganese induced immune suppression of the lobster, Nephrops norvegicus. Aquatic Toxicology 70:223-231.

Hose, J. E., G. G. Martin, and A. S. Gerard. 1990. A decapod hemocyte classification scheme integrating morphology, cytochemistry, and function. Biological Bulletin 178:3345.

Iwanaga, S., and B. L. Lee. 2005. Recent advances in the innate immunity of invertebrates. Journal of Biochemistry and Molecular Biology 38:128-150.

Jiravanichpaisal, P., E. Bangyeekhun, K. Soderhall, and I. Soderhall. 2001. Experimental infection of white spot syndrome virus in freshwater crayfish Pacifastacus leniusculus. Diseases of Aquatic Organisms 47:151-157.

Jiravanichpaisal, P., B. L. Lee, and K. Soderhall. 2006. Cellmediated immunity in arthropods: hematopoiesis, coagulation, melanization and opsonization. Immunobiology 211:213-236.

Johansson, M. W., P. Keyser, K. Sritunyalucksana, and K. Soderhall. 2000. Crustacean haemocytes and haematopoiesis. Aquaculture 191:45-52.

Jussila, J., J. Jago, E. Tsvetnenko, B. Dunstan, and L. H. Evans. 1997. Total and differential haemocyte counts in western rock lobsters (Panulirus cygnus George) under post-harvest stress. Marine and Freshwater Research 48:863-867.

Jussila, J., S. McBride, J. Jago, and L. H. Evans. 2001. Hemolymph clotting time as an indicator of stress in western rock lobster (Panulirus cygnus George). Aquaculture 199:185-193.

Le Moullac, G., and P. Haffner. 2000. Environmental factors affecting immune responses in Crustacea. Aquaculture 191:121-131.

Le Moullac, G., C. Soyez, D. Saulnier, D. Ansquer, J. L. Avarre, and P. Levy. 1998. Effect of hypoxic stress on the immune response and the resistance to vibriosis of the shrimp Penaeus stylirostris. Fish and Shellfish Immunology 8:621-629.

Lorenzon, S., S. De Guarrini, V. J. Smith, and E. A. Ferrero. 1999. Effects of LPS injection on circulating haemocytes in crustaceans in vivo. Fish and Shellfish Immunology 9:31-50.

Lorenzon, S., M. Francese, V. J. Smith, and E. A. Ferrero. 2001. Heavy metals affect the circulating haemocyte number in the shrimp Palaemon elegans. Fish and Shellfish Immunology 11:459-472.

Lorenzon, S., P. G. Giulianini, S. Libralato, M. Martinis, and E. A. Ferrero. 2008. Stress effect of two different transport systems of the physiological profiles of the crab Cancer pagurus. Aquaculture 278:156-163.

Lorenzon, S., P. Pasqual, and E. A. Ferrero. 2002. Different bacterial lipopolysaccharides as toxicants and stressors in the shrimp Palaemon elegans. Fish and Shellfish Immunology 13:27-45.

Owens, L., and A. O'Neill. 1997. Use of a clinical flow cytometer for differential counts of prawn Penaeus monodon haemocytes. Diseases of Aquatic Organisms 31:147-153.

Sequeira, T., D. Tavares, and M. Arala-Chaves. 1996. Evidence for circulating hemocyte proliferation in the shrimp Penaeus japonicus. Developmental and Comparative Immunology 20:97-104.

Sequeira, T., M. Vilanova, A. Lobo-da-Cunha, L. Baldaia, and M. Arala-Chaves. 1995. Flow cytometric analysis of molt-related changes in hemocyte type in male and female Penaeus japonicus. Biological Bulletin 189:376380 .

Shapiro, H. M. 2003. Practical flow cytometry. Wiley, Hoboken, New Jersey.

Smith, V. J. 1991. Invertebrate immunology: phylogenetic, ecotoxicological and biomedical implications. Comparative Haematology International 1:61-76.

Smith, V. J., R. J. Swindlehurst, P. A. Johnston, and A. D. Vethaak. 1995. Disturbance of host defence capability in the common shrimp, Crangon crangon, by exposure to harbour dredge spoils. Aquatic Toxicology 32:43-58.

Soderhall, K., and V. J. Smith. 1983. Separation of the haemocyte populations of Carcinus maenas and other marine decapods, and prophenoloxidase distribution. Developmental and Comparative Immunology 7:229239.

Sokal, R. R., and F. J. Rohlf. 1973. Introduction to biostatistics. Freeman, San Francisco.

Tankere, S. P. C., P. J. Statham, and N. B. Price. 2000. Biogeochemical cycling of $\mathrm{Mn}$ and $\mathrm{Fe}$ in area affected by eutrophication: the Adriatic Sea. Estuarine Coastal and Shelf Science 51:491-506.

Theopold, U., O. Schmidt, K. Soderhall, and M. S. Dushay. 2004. Coagulation in arthropods: defence, wound closure and healing. Trends in Immunology 25:289-294.

Travers, M.-A., P. M. da Silva, N. LeGoic, D. Mavie, A. Donual, S. Huchette, M. Koken, and C. Paillard. 2008. Morphologic, cytometric and functional character- 
ization of abalone (Haliotis tuberculata) haemocytes. Fish and Shellfish Immunology 24:400-411.

Tsvetnenko, E., S. Fotedar, and L. Evans. 2001. Antibacterial activity in the haemolymph of western rock lobster, Panulirus cygnus. Marine and Freshwater Research 52:1407-1412.

Ward, R. J. S., C. R. McCrohan, and K. N. White. 2006. Influence of aqueous aluminum on the immune system of the freshwater crayfish Pacifasticus leniusculus. Aquatic Toxicology 77:222-228.

Xue, Q.-G., T. Renault, and S. Chilmonczyk. 2001. Flow cytometric assessment of haemocyte sub-populations in the European flat oyster, Ostrea edulis, haemolymph. Fish and Shellfish Immunology 11:557-567.

Yip, E. C. H., and J. T. Y. Wong. 2002. Fluorescence activated cell-sorting of haemocytes in penaeid prawns. Aquaculture 204:25-31. 